\title{
Implementing Local Open-Source Network-Attached Storage for Higher Education Institution
}

\author{
Jorrish D. Alcantara \\ San Carlos Collge \\ Brgy. Tambac, San Carlos City \\ Pangasinan, Philippines
}

\author{
Angelo T. Calimlim \\ San Carlos College \\ Brgy. Mapolopolo, Basista \\ Pangasinan, Philippines
}

\author{
Bernard Jorge Dayag \\ San Carlos College \\ Brgy. Batangcaoa Bayambnag \\ Pangasinan, Philippines
}

\begin{abstract}
Nowadays organizations, institutions, etc. are storing their data, record and other significant file locally or cloud. Storage is very important for educational institutions and other businesses to store and protect all data such as employee's personal information, assessment records of the students, school maintenance budget plans, payrolls of employee and accounts of students, etc. It is important that all of those data are secured and stored properly because some of this data are stating money and other private information needs to be secure and safeguard. The proposed project is an appropriate solution in the current storage problems in the basic education department. The local open-source network attached storage resolves the issues of the storage in San Carlos College basic education department. The principal/administrator, coordinators and users can manage their files in their assigned folders and also they are contented that the files that they stored is secured since files and folders of admin and coordinators cannot be accessed by others.
\end{abstract}

\section{Keywords}

Local Open-Source Network-Attached Storage, FreeNAS, Snapshots, ZFS, Network Attached-Storage Data Protection

\section{INTRODUCTION}

\subsection{Project Analysis}

Nowadays organizations, institutions, etc. are storing their data, record and other significant file locally or cloud. Storage is very important for educational institutions and other businesses to store and protect all data such as employee's personal information, assessment records of the students, school maintenance budget plans, payrolls of employee and accounts of students, etc. It is important that all of those data are secured and stored properly because some of this data are stating money and other private information that needs to be secured and safeguarded. Increasing size of data, security, accessibility, file sharing etc. depends on how fast the internet connection. Storing files to the cloud storage rally depends on how fast the internet connection and it could result to the slow performance of the computer. Based on the stated grounds, the proponents believe that it is very timely to implement a local open-source network attached storage for educational institution.

\subsection{Project Framework}

To make the proposed project feasible, the study followed a framework that serve as the pattern of operations.

Figure 1 is the framework of the proposed local open-source network attached storage and how it is working. Based on user requirements, system requirements determined such as the storage capacity, the needed memory, and machine's specification. Knowing the hardware requirements, configuration of the local open-source network attached storage will done. Features such as file sharing, web interface, data protection, snapshots, replication and encryption are set. This features are set up according to the user's requirements. The proposed project can be accessed through the use of browser, client's computer of different platform can access and manage it. Operating systems such as Windows, Android, iOS, Linux and BSD can be used as long as it is installed with an internet browser capable of accessing the proposed storage facility.

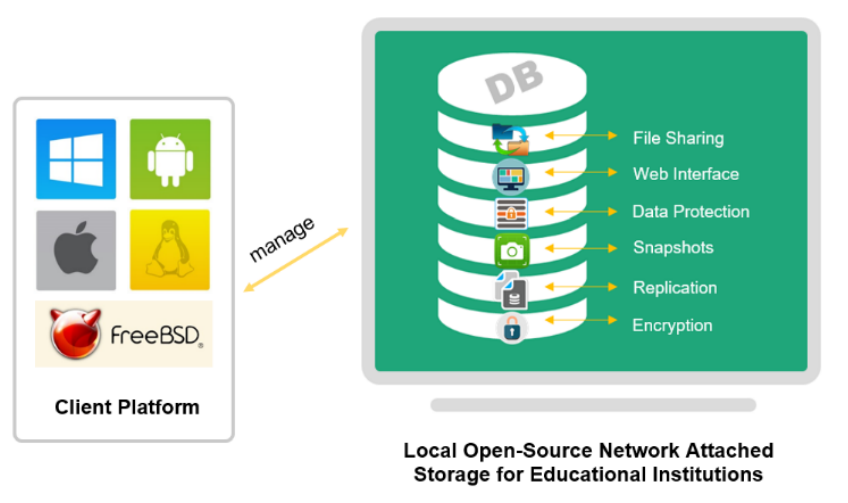

Fig 1: Operational Framework

\section{RELATED LITERATURE}

${ }^{1}$ IT pros said they were concerned with a variety of issues that caused data loss in the business. $31 \%$ of them said that hardware or system caused the failure, and $29 \%$ is lost data due to human error, and $29 \%$ mentioned that viruses malware or ransomware led to data loss. With what devices were most of failure cause of data loss, IT professionals said that the laptops are mostly to blame by $39 \%$. $26 \%$ said they are worried about servers, and another $26 \%$ about desktops. Only $4 \%$ were concerned about tablets and mobile devices failing and causing data loss. ${ }^{2}$ Usability testing end up to be incredibly valuable in user interface design. Watching users interact with the software taught the proponents some of the pitfalls in software's initial design.

\footnotetext{
${ }^{3}$ FreeNAS is compatible with all support of FreeBSD. And it supported a array chipset and network controllers. FreeBSD or BSD "Berkeley Software Distribution" and base on Greg Lehey ${ }^{4}$ BSD kernel can handle scheduling, memory management, symmetric multi-processing device drivers that we have BSD in our NAS to support the other files and to manage the memory. These ensures that FreeNAS can connect different operating system's file sharing regardless of the the platform they are using. . iXsystem ${ }^{5}$ that if fast performance is to be desired, it will need a 64-bit machine. 64-bit is the recommended to use in NAS. With the use of open-source network attached storage, institution can assure that those files is well protected. Most of computer nowadays
} 
are in 64-bit and there is no problem in finding one. ${ }^{6}$ Ritika Tiwara says that the cloud is important to all individuals in order for them to secure cloud their data by backing it up. A backup should include saving duplicate data. Having duplicate copies of your most important data is really important for unforeseen circumstances such as crashing of compilers, virus infection and others

\section{METHODOLOGY}

\subsection{Population and Locale}

\subsubsection{Population}

Stakeholders involved in this project includes principal, teachers, and the IT personnel in the basic education department. The proposed program is tested by the teachers and evaluated the features intended are properly setup or configured. Teachers and the IT personnel attest the local open-source network attached storage if the desired functionality of the project has been appropriately working. Not all employees are asked to test but a sample population are not enough to evaluate the feasibility and acceptability of the proposed project.

\subsubsection{Locale}

The proposed study is conducted in San Carlos College located at Mabini St., San Carlos City, Pangasinan. San Carlos College, formerly PIEAS, was founded in the 1946 by late Atty. Fortunato Concepcion De Veyra. San Carlos College offers wide variety of programs from Kindergarten up to Masters Level. San Carlos College has its own MIS Department which manages all the IT-related facilities of the institution. Collaboration between the basic education department is done for the testing and implementation of the proposed project.

\subsection{Data Instrumentation}

In order to design the proposed project entitled local opensource network attached storage for educational institution, different data gathering techniques was employed such as internet web browsing, interviews and observations.

\subsubsection{Internet or Web Browsing}

It is used to view local files on a computer like text documents and XML which is also used to communicate in different forms such as email and videos. Proponents utilized the internet or web browsing as one of their source of information for the project. Browsing in the internet gives the proponents more knowledge in the said project. If the proponents encountered some issues and major problems in their research the proponents can use the internet to browse more updates.

\subsubsection{Interview}

A research interview involves an interviewer, who coordinates the process of the conversation and asks questions, and an interviewee, who responds to those questions. Interviews can be conducted face-to -face or over the telephone. The internet is also emerging for a tool for interviewing. In conducting an interview the proponents asked some survey questions to all users who have access to the organization's files and folders. After having survey and after taking notes on all the problems that they encountered, the proponents analyzed and researched on it in order to come up with a good solution to the problems and issues.

\subsubsection{Survey}

It is a commonly used method of collecting information about organizations interest. It is also the opportunity to execute studies with various designs, each of which is suitable for addressing particular research questions and also addition of casual evidence in building documents and acceptability to a project. Having a survey for the IT personnel Mr. Relson R. Peralta and other teachers who have a different access to the organization will be more efficient rather than asking for the person who are handling them. Using survey, the project is be able to be evaluated by the employee, heads, and the basic education department in terms of its feasibility and effectivity. Survey form is prepared after the implementation of the said project and has been administered to the principal, IT personnel and teachers. Survey forms serve as acceptance and feedback tool of the stakeholders for the proponents' proposed project.

\subsection{Data Analysis}

The proponents choose network development life cycle as the methodology that will be used for the proposed study. Figure 2 shows the network development life cycle and its phases.

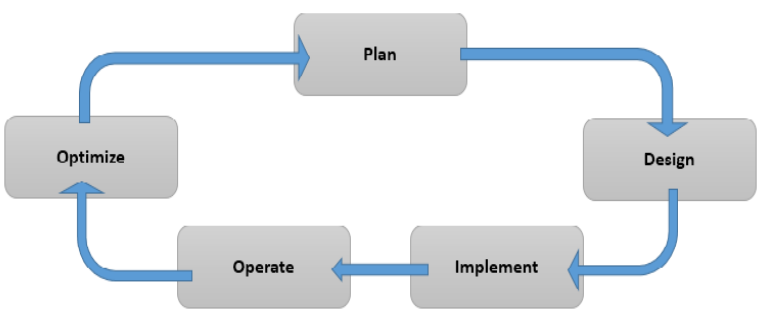

Figure 2: Network Development Life Cycle

The network development life cycle model comprises of five expressive phases as described in figure 2 these are plan, design, implement, operate and optimize. These phases were elaborated below:

\subsubsection{Plan}

This phase is the first step wherein it involves the planning and gathering of relevant information for the proposed project. The proponents conducted a research and surveys about the feasibility of implementing local open source network attached storage, how it works and the probably issues that this encountered. The proponents also searched for the most appropriate software for the requirement that is userfriendly, feature-packed and economical. Stakeholders can also be identified in order to determine the people who need to be interviewed to acquire necessary inputs for the furtherance of the study.

\subsubsection{Design}

This phase usually represented as network diagram that serves as the blueprint for of implementing the project physically. After the planning phase, next step is the design phase. The proponents design the network infrastructure of the proposed project. Since there is an existing network, this network can be evaluated to know if it is enough for the said project. If not, necessary adjustment have been done to make it suitable for the project. The proponents configured the local open-source network attached storage so that the requirement fit to the users. The user can access the data depends on the permission given by the server.

\subsubsection{Implement}

In this phase, the finished design was implemented. The proponents implemented the project upon the approval and agreement with the Basic Education Department of San Carlos College. Although, testing and demonstration of the 
proposed study is conducted in the Basic Education Department of the San Carlos College. Necessary hardware devices are installed, setup and configured and it is placed in strategic location which will be determined by the basic education department

\subsubsection{Operate}

Operate is the process of actually using the proposed project. The project is operated in order to test its effectiveness. This phase covers all day to day operation and maintenance of the local open-source network attached storage. Actual files are sync on the network attached storage and its features such as replication, encryption, security, and file sharing will be tried and tested. With the assistance of the basic education department IT personnel Mr. Relson R. Peralta and participation of the teachers, the operation and testing of the said project has took place.

\subsubsection{Optimize}

This is the final phase where the feedbacks coming from the stakeholders are considered. The proponents had optimized the network attached storage based on the comments, suggestions and recommendations of the basic education department. At the end of the implementation period, the proponents conducted interviews and administered surveys to determine the effectiveness of the proposed project.

\section{PRESENTATION AND INTERPRETATION OF DATA}

\subsection{Description of the Project}

Local open-source network attached storage aims to manage files and folders of the San Carlos College Basic Education Department in one storage. All stakeholders can access the said storage but there are some areas in the storage that they can't be accessed except unless with permission. The admin can access the whole files and folders because the admin has full control in the storage. The coordinator can access the coordinators folder and the teachers' folder because of the permission. There is a folder that the coordinators can't access and that is the folder of the admin. Each of the coordinators have their own folder, when the coordinator login in to their folder they can't access the folder of the other coordinators. The teachers can only access the teachers' folder, they can't access the coordinators' folder and the admin's folder.

The network attached storage is installed because it has a lot of features that basic education department can use and it will be placed in the principal's office because the principal requested the proponents that the server will be placed in the principal's office. The principal request to the proponents that the said project should be deployed in her office because according to her, she is old and she can't hardly use the stairways going up to the 2nd floor. Also, according to the principal if calamities come the said project can be moved from the faculty room with her IT personnel.

\subsection{Network Development Life Cycle}

The network development life cycle (NDLC) was used by the proponents because the process involved in the cycle intends to describe the phase of server to client accessibility and permissions of the said storage. Proponents choose a network development life cycle that need the necessary thing to the proposed study. NDLC is easy to understand and can provide more detailed information on technology and process which can help the proponents finish the project.

\subsection{Plan Phase}

The plans created during this phase, the proponents manage time, quality and risk and issues. In this phase, proponents gave a request letter that is signed by the stakeholders and the chairman of defense panel Mr. Romulo L. Olalia Jr. to conduct the said study. After giving the request letter, the existing storage in the institution, and proponents found out that files are stored on compact disc (CD). CD as serves as the storage of the institutions. Based on the results the implementation in this phase, step by steps instruction including test configuration and roll back plans in case of error of things. The proponents started the plan phase by gathering information and list down the requirements including all services requirement and security requirements. The proponents need to ensure the storage security by planning and designing the NAS. The Proponents can assume that the document or other multimedia files of the basic education department of san carlos college are secured and safe.

\subsection{Design Phase}

The design is based the users organizational chart of the Basic Education of San Carlos College based on it the main user and the admin assigned its possible user its possible clients. The proponents design the proposed study in the san carlos college in basic education. The proponents gathered an information about their storage and the proponents find out that they stored their files and folders in compact disc. One time a typhoon occurs their storage soaked in flood so their files and folders was destroyed. Proponents design the folders according to the teacher's program. Proponents placed the server in the principal's office and the server is connected to a router then the teachers connected to the router so that they can access the said storage.

The principal's office network have an independent network it is not connected on the other networks that shown in the existing network layout in Figure 4.6. The other connection of the basic education department supported from the internet connection of the faculty this network supports the every room who have Quipped. Network infrastructure is the hardware and software resources of an entire network that enable network connectivity, communication, and management of a network. The proponents use packet tracer to layout the San Carlos College and the proponents will implement the NAS in Basic Education. This is the network infrastructure of NAS which shows how the flow of storage. In their existing network the Principal's office have a independent network. The connection in faculty serves as the main server of the coordinator's office and the coordinators office serves a server of the network of every room that have a Quipper.

The proponents create a visual platform simulation tool using packet tracer software made by Cisco to illustrate the existing network of the Basic Education Department of San Carlos College. The software allows the proponents to simulate the configuration of routers and switches using a simulated command line interface. To access the storage the users need to connect to their laptops, computers or mobile devices through Wi-Fi of the Principal's office to access the storage. The visual simulation of the existing IT facilities of Basic Education Department of San Carlos College discuss their current connections of their networks. The principal's office have a independent connection of network with one router and a switch with a two(2) personal computers one of the computer is used as a storage of data and files and the another uses a personal use of the principal. 


\subsubsection{Folder Hierarchy}

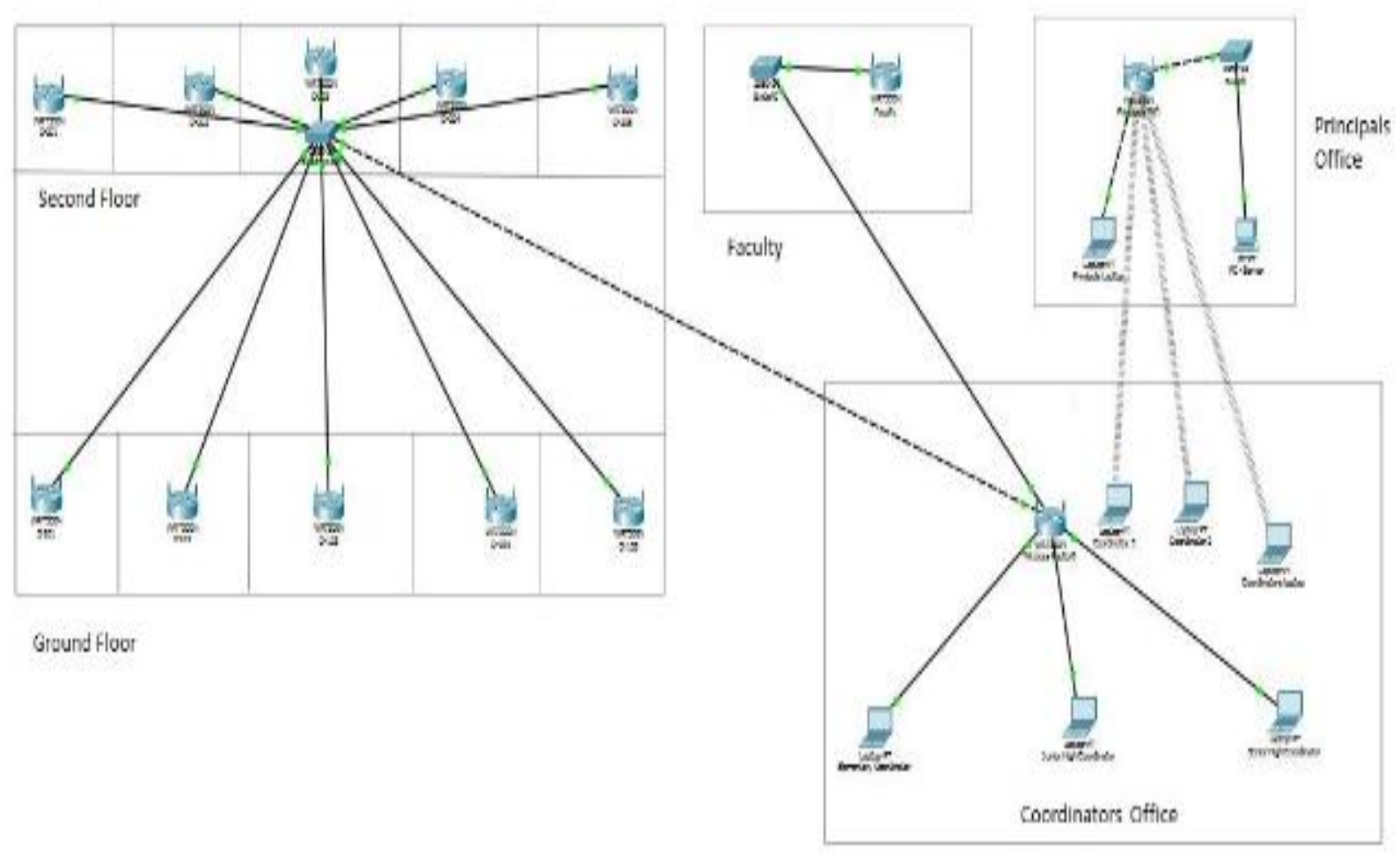

Figure 3: Network Infrastructure

The proponents create a multiple folders for the accessibility of the admins and user's. The figure 4 shows represents the folder arrangement of the Basic Education Department Files. The proponents create a volume named Basic Education Department, the proponents also created a dataset under it named Basic Education Department Files this dataset has a one dataset named Coordinator's Files. A dataset for Dr. A. Peralta is also created and under it is the coordinator file dataset with is also be controlled and manage by the principal and the coordinators. After creating the coordinator's files dataset the proponents create a three 5 datasets under the Coordinator's files those dataset's named Elementary, Junior High, Senior High, Principal's files and Teacher's Folder it is shown in the figure above. After creating those datasets the proponents created a folders in each datasets those folders are the names of sections that is handled of each coordinator's each folders contains files of every teacher's. Only one coordinator have a full access on her/his desired dataset except from the principal. The teachers folder datasets is owned by nobody, this dataset have a full control of all coordinators even teachers too. The deployment of all files needed will be checked by the principal and coordinators.

\subsection{Implement Phase}

During this phase, the proponents implement the local opensource network attached storage in the principal's office. This stage is the part where the proponents will place the storage in the principal's office and setup the given requirements that the stakeholders told to the proponents. The proponents were assembled a physical computer that is utilized by the proponents for FreeNAS software and made a prototype NAS computer to configure and reconfigure the setting before the proponents implement the proposed study to San Carlos College. And the clients tried the proposed study if the proposed study is working and safe. Afterwards discuss all information that the clients need to gather and the clients are all satisfied for the next project the clients only need some sort of exploration for further information on the said project.

\subsection{Optimize Phase}

The proponents utilized the network in the principal's office. To access the said storage, teachers needed to connect to the Wi-Fi in the principal's office. Proponents did not modify the existing network of the basic education department that uses for Quipper because the proponents deploy the said project in the principals network. The server is located at the principal's office located at the ground floor De Veyra Building. The proponents install the freeNAS operating system properly after installing the said project proponents configure the storage and they configured it according to the requirements of the stakeholders. 


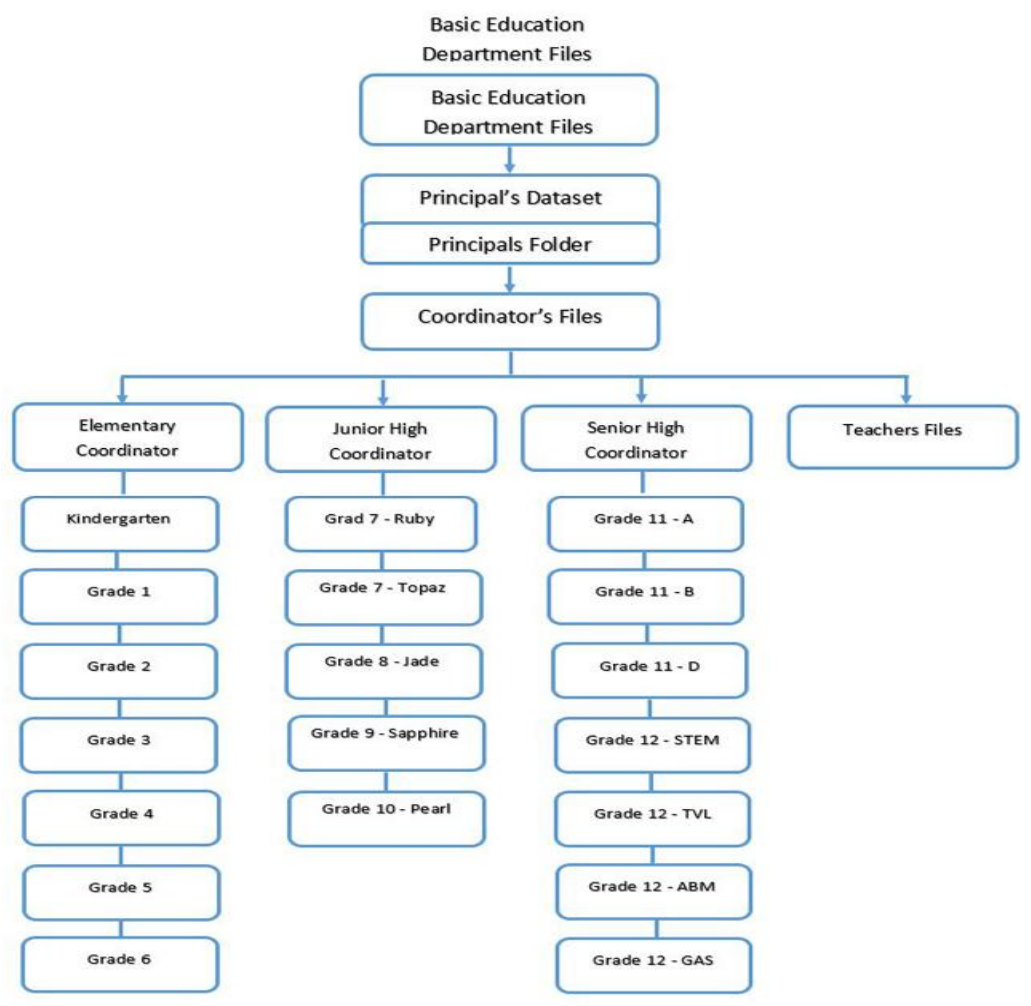

Figure 4: Folder Arrangement

\subsection{Survey Result}

Upon the evaluation, 20 evaluators agreed that the network attached storage is a server that can solve the issues that they encountered before. 20 respondents said that they can easily access the storage. But eight(8) only got an average score of 93\% because one(1) respondent didn't understand the process of managing files despite the proponents discussion on the latter. Some files according to the evaluators are not accessible because the proponents created an account in every dataset in the system without a permission to the owner the user cannot access all the files in the folder that was given to others. 93\% respondents said that they cannot access the storage through mobile device because they did not try to access the storage through mobile except their IT personnel, only the IT personnel tried to access the storage through mobile device having an average result of $7 \%$. The proponents gathered a $100 \%$ results for other (15) questions because they did not encounter some errors in the system they can access the system over the network and they are agree also that there's is an authentication procedure before they can login and they can access files over the network. After accessing the files they can create a files and or folders on the system and also based on the result they can also edit the files or folder on the system. They can manage files and folders through their accounts. According to the survey the system also has a user friendly interface because all of them agreed that the system storage is easy to use. All files that the users stored in the system surveys says that they can backup and restore all the data that is accidentally deleted. Also according to the survey the system can be accessed through mobiles devices such as laptops, tablets and or mobile phones. The evaluators agreed also that they can access the system through wired and wireless network. The evaluators agreed also that their time of uploading files are lessen in short the system is faster in uploading files as compared to the other system that they are using. Based on the result of the proponents survey they received a $93 \%$ of acceptance for the system and the effectivity of it reflects from the survey form above $7 \%$ of it are in negative feedback to the question because they need some practice and some idea about the system.

Tables.4 Survey Result

\begin{tabular}{|l|c|c|}
\hline \multicolumn{1}{|c|}{ QUESTIONS } & YES & NO \\
\hline Can you access the network-attached storage over the network? & 20 & 0 \\
\hline $\begin{array}{l}\text { Is there an authentication procedure before accessing the network-attached } \\
\text { storage? }\end{array}$ & 20 & 0 \\
\hline Can you access your files over the network? & 20 & 0 \\
\hline Can you create file/s and/or folder/s within your assigned folder? & 20 & 0 \\
\hline Can you edit your own file? & 20 & 0 \\
\hline Can you access files that are shared with you or with other users? & 20 & 0 \\
\hline $\begin{array}{l}\text { Does the facility allows you to access files or folders that are not yours or not } \\
\text { shared to you? }\end{array}$ & 0 & 20 \\
\hline $\begin{array}{l}\text { Did the user easily understood the process of managing files in the network- } \\
\text { attached storage? }\end{array}$ & 19 & 1 \\
\hline Does the storage facility allows storage of different file types? & 20 & 0 \\
\hline Is the storage facility easy to use? & 20 & 0 \\
\hline Did you feel that the storage facility secures your files accordingly? & 20 & 0 \\
\hline $\begin{array}{l}\text { Does the storage facility allows the backup and restoration of the files and/or } \\
\text { folders stored? }\end{array}$ & 20 & 0 \\
\hline $\begin{array}{l}\text { Can the storage facility be access in mobile devices such as laptops, tablets } \\
\text { and/or mobile phone? }\end{array}$ & 20 & 0 \\
\hline Is the storage facility be access either through wired network or wirelessly? & 20 & 0 \\
\hline $\begin{array}{l}\text { Does the system have fast upload time than other storage system? Would you } \\
\text { recommend the use of this network-attached storage facility for the ease and } \\
\text { security of handling and managing files? }\end{array}$ & 20 & 0 \\
\hline
\end{tabular}




\section{SUMMARY, CONCLUSION AND RECOMMENDATION}

\subsection{Summary of Findings}

The basic education department has 3 different networks and it is located in De Veyra Building, the first network is located at the in principal's office and the principal is the only one who is connected to that network, the second network is located at the office of the coordinators office, and the last network is located at the 2nd floor in the faculty room located at the De Veyra Building. The connection in the faculty serves as the main server of the coordinators' office and the coordinators' office serves as server of the network of every room that have a Quipper. San Carlos College Basic Education Department has a storage and it is located at the office of the principal. One time their storage have been soaked during the typhoon so their storage has been damaged and all of their files are gone. The Basic Education Department is using a compact disc (CD) to store their files and data this is prone to risk and possible security issues. The clients don't have an efficient system for the backup of their files in case of those CD's and computers are ruined. The main server or storage of their files are too slow in uploading files even if it is online. The existing network infrastructure of the Basic Education of San Carlos College have 3 different networks it is hard to define where can the proponents deploy the project. The coordinators and teachers need permission to upload their files when they need to connect in the internet. During the testing stage, FreeNas was tested and evaluated by the clients. According to the result of the survey form shown in Figure 3. $93 \%$ of the clients answered positively because they can access the user interface of the system through their laptops and smartphones along as it is connected to the network.

\subsection{Conclusion}

Network Attached Storage is an operating system that is employed in the proposed project local open-source network attached storage. The proposed project is an appropriate solution in the current storage problems in the basic education department. The local open-source network attached storage resolves the issues of the storage in San Carlos College basic education department. The principal/administrator, coordinators and users can manage their files in their assigned folders and also they are contented that the files that they stored is secured since files and folders of admin and coordinators cannot be accessed by others. Based on the result of the proponents survey they received a $93 \%$ of acceptance for the system and the effectivity of it reflects from the survey form above $7 \%$ of it are in negative feedback to the question because they need some practice and some idea about the system.

\subsection{Recommendations}

The Basic Education Department of San Carlos College need to upgrade their storage. Because they are using $\mathrm{CD}$ (compact disk) as their storage it has no security type of system for them to keep their files safe.

\section{REFERENCES}

[1.] StorageCraft TechCor (Data Loss Statistics ). https://blog.storagecraft.com/data-loss-statisticsinfographic/

[2.] Colleen Knuff(The Importance of Good User Interface Design)http://www.teammatesolutions.com/theimportance-of-good-user-interface-design.aspx

[3.] Marco Chiappetta., June 2014 "Turn old pc hardware into a home server with FreeNAS"https://www.pcworld.com/article/2243748/tur n-old-pc-hardware-into-a-killer-home-server-withFreenas.html

[4.] Greg Lehey (n.d) "Explaining BSD". https://www.freebsd.org/doc/en_US.ISO88591/articles/explaining-bsd/article.html

[5.] iXsystem. 2014 "FreeNAS 9.2.1 USERS GUIDE". http://web.freenas.org/images/resources/freenas9.2.1/free nas9.2.1_guide.pdf

[6.] Ritika Tiwari., (5 Reasons Why Cloud Security is Important for SMBs). https://www.cloudwards.net/5reasons-why-cloud-security-is-important-for-smbs/ 